University of Nebraska - Lincoln

DigitalCommons@University of Nebraska - Lincoln

Mammalogy Papers: University of Nebraska

State Museum

Museum, University of Nebraska State

2008

\title{
A Simple Morphological Predictor of Bite Force in Rodents
}

Patricia W. Freeman

University of Nebraska-Lincoln, pfreeman1@unl.edu

Cliff A. Lemen

University of Nebraska-Lincoln, clemen2@unl.edu

Follow this and additional works at: https://digitalcommons.unl.edu/museummammalogy

Part of the Zoology Commons

Freeman, Patricia W. and Lemen, Cliff A., "A Simple Morphological Predictor of Bite Force in Rodents" (2008). Mammalogy Papers: University of Nebraska State Museum. 117.

https://digitalcommons.unl.edu/museummammalogy/117

This Article is brought to you for free and open access by the Museum, University of Nebraska State at DigitalCommons@University of Nebraska - Lincoln. It has been accepted for inclusion in Mammalogy Papers: University of Nebraska State Museum by an authorized administrator of DigitalCommons@University of Nebraska Lincoln. 


\title{
A Simple Morphological Predictor of Bite Force in Rodents
}

\author{
Patricia W. Freeman and Cliff A. Lemen
}

School of Natural Resources and University of Nebraska State Museum, University of Nebraska-Lincoln, Lincoln, NE, USA Corresponding author - P. W. Freeman, School of Natural Resources and University of Nebraska State Museum, 428 Hardin Hall, University of Nebraska-Lincoln, Lincoln, NE 68583-0974, USA; email pfreeman1@unl.edu

\begin{abstract}
Bite force was quantified for 13 species of North American rodents using a piezo-resistive sensor. Most of the species measured (11) formed a tight relationship between body mass and bite force $\left(\log 10\right.$ (bite force) $=0.43\left(\log 10(\right.$ body mass) $\left.)+0.416 ; R^{2}>0.98\right)$. This high correlation exists despite the ecological (omnivores, grazers and more carnivorous) and taxonomic (Cricetidae, Heteromyidae, Sciuridae and Zapodidae) diversity of species. Two additional species, Geomys bursarius (Geomyidae) and a Sciurus niger (Sciuridae), bit much harder for their size. We found a simple index of strength based on two measurements of the incisor at the level of the alveolus $\left(Z_{i}=\left((\text { anterior-posterior length })^{2} \times(\right.\right.$ medial-lateral width $\left.\left.)\right) / 6\right)$ that is highly predictive of bite force in these rodents $\left(R^{2}>0.96\right)$. $\mathbf{Z}_{\mathrm{i}}$ may be useful for prediction of bite force $\left(\log 10\right.$ (Bite Force) $\left.=0.566 \log 10\left(\mathbf{Z}_{\mathrm{i}}\right)+1.432\right)$ when direct measurements are not available.
\end{abstract}

Keywords: rodent, jaw, bite force, ecomorphology, biomechanics

\section{Introduction}

Using a newly developed bite force sensor (Freeman \& Lemen, 2008) we measured bite force in 13 species of rodents. Part of our goal here was to see whether bite force in these rodents was correlated with their feeding ecology. We divided these species into trophic categories that included omnivores (Peromyscus, Perognathus, Dipodomys, Reithrodontomys, Spermophilus, and Onychomys), grazers (Microtus, Sigmodon), nut eaters (Sciurus) and a fossorial species (Geomys) along the same lines as Aguirre et al. (2002) in their study of a bat community. Separation of these rodents into ecological categories is a bit arbitrary (Landry, 1970), but we feel these categories have some validity.

We also looked for morphological characteristics that can be used to predict bite force. We are not using a jaw mechanics approach where detailed information is needed on muscle mass, insertion points and input and output arms (Maynard Smith \& Savage, 1959; Turnbull, 1970; Hiiemae, 1971; Thomason, 1991). Ultimately such models try to combine force and input and output arms in a descriptive model. Our approach is purely descriptive; to find an easily measured morphological index that accurately correlates with bite force measured in the field. Body weight can be used to predict bite force. However, this overlooks possible differences in species based on feeding ecology and not size, as in the difference in the wolf and the bone-crushing hyena (Binder \& Van Valkenburgh, 2000; Meers, 2002; but see Wroe et al., 2005). We assume that the more powerful the bite, the stronger the jaws must be to resist break- ing. We test this hypothesis with three indices that measure different aspects of strength. First the cross-sectional area at location $x$ on the jaw which is simply

$$
\mathbf{A}=h w
$$

where $h$ is the height of the beam and $w$, its width. $A$ is an index of strength of a rectangular column to axially applied loads (Popov, 1999) because stress attributable to axial loading is proportional to load/A. Note all strength indices used here are not absolute measures of strength. To obtain those estimates the material properties of bone and teeth would have to be incorporated into the model. Our second index of strength is the section modulus $\mathbf{Z}$ (Popov, 1999):

$$
\mathbf{Z}=w h^{2} / 6
$$

where $\mathbf{Z}$ is an index of a rectangular cross-section's ability to resist a bending moment. However, it does not take into consideration the distance to the load. An index of bending strength that takes both $\mathbf{Z}$ and input arm into consideration can be found by altering the stress equation for a rectangular beam:

$$
\sigma=l_{x} P / \mathbf{Z}
$$

where $\sigma$ is the bending stress in a beam at location $x, l_{x}$ is the distance from the load to location $x$ and $P$ is the load. Equation (3) is intuitively satisfying because it is a ratio of bending moment (numerator) and cross-sectional strength (denominator), but it is not an index of strength. First, stress is inversely related to strength so we use the reciprocal of stress. Second, equation (3) includes the load $P$ which is not 
part of the beam's strength. To fix this we substitute a load of 1 into equation (3) to yield

$$
\mathbf{S}=\mathbf{Z} / l_{x}
$$

where $\mathbf{S}$ is an index of bending strength. Note that equation (4) is simply the ratio of a cross-section's ability to resist a bending moment divided by the input arm length. It is this ratio that determines the relative strength of a crosssection relative to its input arm (Van Valkenburgh \& Ruff, 1987).

Two locations on the dentary were chosen for measurement: the base of the incisor and the midpoint of the diastema (Figure 1). We test the usefulness of these indices and body mass for predicting bite force.

\section{Materials and methods}

We measured bite force on 94 individuals of 13 species (Cricetidae: Microtus ochrogaster, Neotoma floridana, Onychomys leucogaster, Peromyscus leucopus, Peromyscus maniculatus, Reithrodontomys megalotis, Sigmodon hispidus; Geomyidae: Geomys bursarius; Heteromyidae: Dipodomys ordii, Perognathus flavescens; Sciuridae: Sciurus niger, Spermophilus tridecemlineatus; and Zapodidae: Zapus hudsonius) by using a piezo-resistive sensor as described in Freeman \& Lemen (2008). Animals were removed from the trap and tested immediately. In all cases bite force was measured at the incisors as the rodent bit the sensor. The strongest bite of each animal was recorded. Testing only lasted about a minute before the animal was weighed and released. Because the bites of the larger rodents could cause damage, thin metal disks were used for a protective covering over the sensor (see Freeman \& Lemen, 2008).

The rodent mandible is complex, but the distal end can be seen as a beam (Landry, 1970 and Figure 1). The beam is made up of the front incisor and the diastema portion of the dentary. We studied two locations on this portion of the jaw. First, the height and width of the dentary about midway between the incisors and the cheek teeth where the diastema dips to its lowest point was measured. The orientation of the height measurement was made to be perpendicular to a line connecting the tip of the incisor to the mandibular condyle. The moment arm was measured from the tip of the incisor to this location on the diastema. Indices associated with the diastema received subscript d: $\mathbf{A}_{\mathbf{d}^{\prime}}$ $\mathbf{Z}_{\mathrm{d}^{\prime}}$ and $\mathbf{S}_{\mathrm{d}}$. The incisor was measured for length (anteriorposterior length) and width (medial-lateral width, see Figure 1) both taken at the level of the dorsal-most rim of the alveolus. The orientation of the anterior-posterior length was perpendicular to the curvature of the incisor. Thus $\mathbf{Z}$ represents resistance to a bending moment in the dorsalventral direction for the diastema and labiolingual direction for the incisor. We did not measure a moment arm for the incisor because we felt it was more subject to measurement error than the longer moment arm for the diastema. Therefore the bending stress for the incisor, $\mathbf{S}_{\mathbf{i}}$, was not calculated.

We assumed a solid rectangular model for the diastema with no consideration of the complex structure of bone and incisor. Other regular shapes, such as an oval could be used, but they would only differ by a constant from our calculations. After mean mass was found for a species, two museum specimens of similar mass were measured and averaged to supply the morphological data.

Freeman \& Lemen (2008) noticed that in some conditions (cold stress), animals did not bite as hard. Therefore we only trapped on mild nights (temperature $>7^{\circ} \mathrm{C}$ ) for this study. There may still be a problem even when care is taken to reduce stress; if some animals do not bite at their hardest, they will create outliers at the low end of bite force. To test for the problem of such outliers, we ran regressions on the data using both the standard least squares model (lm model in R; R Development Core Team, 2005) and a robust regression (rlm in MASS package in R using Huber method). Further when computing relative bite force as residuals from the regression of bite force to body mass, we used both mean and median to test for the impact of outliers.

Although absolute bite force is important, we also found the relative bite force by using the residuals from a linear regression of the log 10 transformations of body mass and bite force. What group of species should be used in the regression? On the surface it seems all species should be included. The problem with this approach is that two of the larger species in our study were the durophagus $S$. niger and fossorial G. bursarius. Because of their size and powerful bites, they would have a large amount of leverage in the regression analysis. This solution would not give the best body mass to bite force relationship. Therefore we chose to use only cricetids to define the regression line. The range in size of these rodents incorporated nearly the entire range of sizes in the study, and these species were more similar in phylogeny and ecological habit.

We use the AIC method on the log 10-transformed regressions for model selection (Burnham \& Anderson, 2002). An estimate of the relative probability of each model was found using AIC weights.

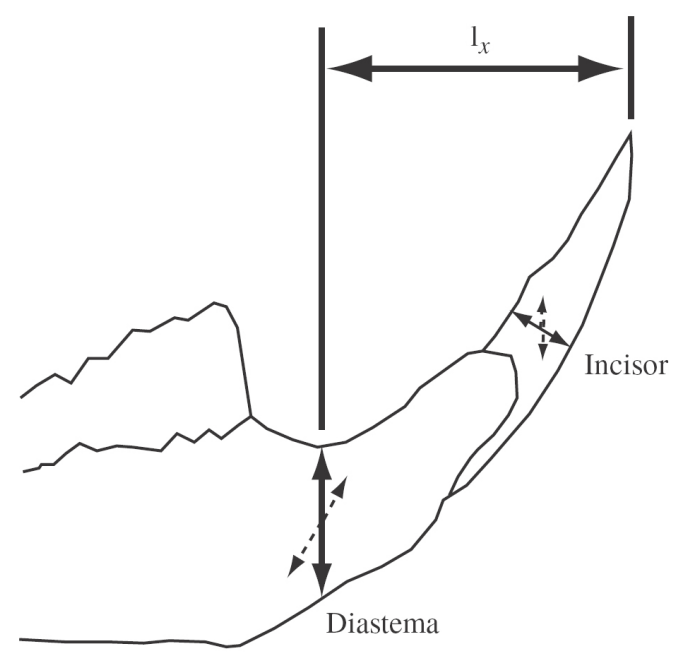

Figure 1. Positions on a rodent's jaw where cross-sectional measurements were made. 


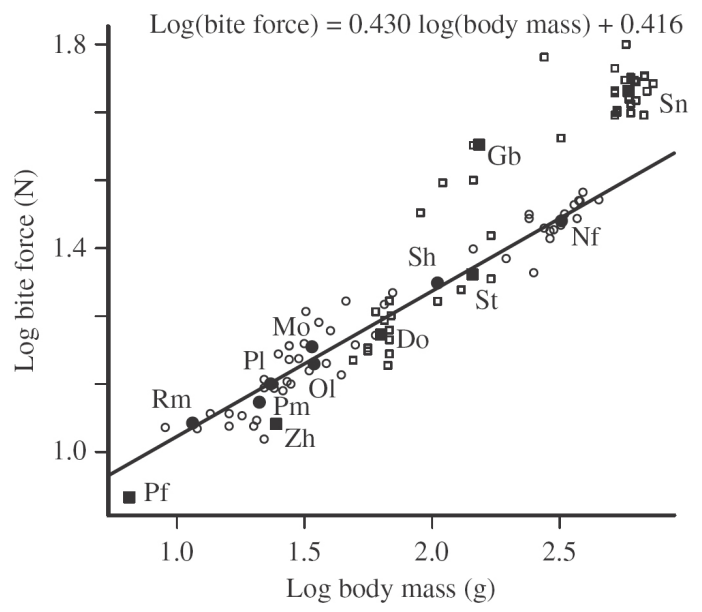

Figure 2. Scattergram of body mass and bite force. Solid symbols are species means, open symbols are individual measurements. Cricetids are plotted as circles and non-cricetids as squares. Regression line plotted is for the measurements from the cricetids only. Species abbreviation are: Dipodomys ordii, Do; Geomys bursarius, Gb; Microtus ochrogaster, Mo; Neotoma floridana, Nf; Onychomys leucogaster, Ol; Perognathus flavescens, Pf; Peromyscus leucopus, PI; P. maniculatus, Pm; Reithrodontomys megalotis, Rm; Sciurus niger, Sn; Sigmodon hispidus, Sh; Spermophilus tridecemlineatus, St; Zapus hudsonius, Zh.

Finite element analysis (FEA) was performed on a simple model of a rodent's jaw using FEMPRO (Version 20, ALGOR). Our models assumed no difference in the material properties of bone and tooth. The three-dimensional model was created from the two dimensions of a drawing of a jaw and the third dimension by giving the jaw a uniform thickness. Principal stresses were used because in our analysis they showed tensile stresses in the jaw at the critical areas with maximum stress.

\section{Results}

We found three lines of evidence that outliers were not a significant problem in these data. First, visual inspection of the data showed no obvious problems as was found in Freeman \& Lemen (2008). Second, there is overall similarity and high correlation of mean and median bite force $\left(R^{2}\right.$ $=0.98$ ). And finally, the near identical results from least squares and robust linear regression of $\log 10$ body mass to $\log 10$ bite force (least squares: slope $=0.430$, intercept $=0.416$; robust: slope $=0.430$, intercept $=0.417$ ). Based on these results we used the more traditional least-square statistics in our analysis.

Figure 2 is a scattergram of mean bite force to body mass by species with the individual data plotted as smaller symbols. The regression for the cricetid data is highly significant (adjusted $R^{2}=0.986 ; P<0.0001$ ), and the regression line is plotted in Figure 2 as well. Deviations above the line represent relatively powerful bites for body weight.

These cricetids form a tight relationship of body weight to bite force that is largely independent of feeding ecol-

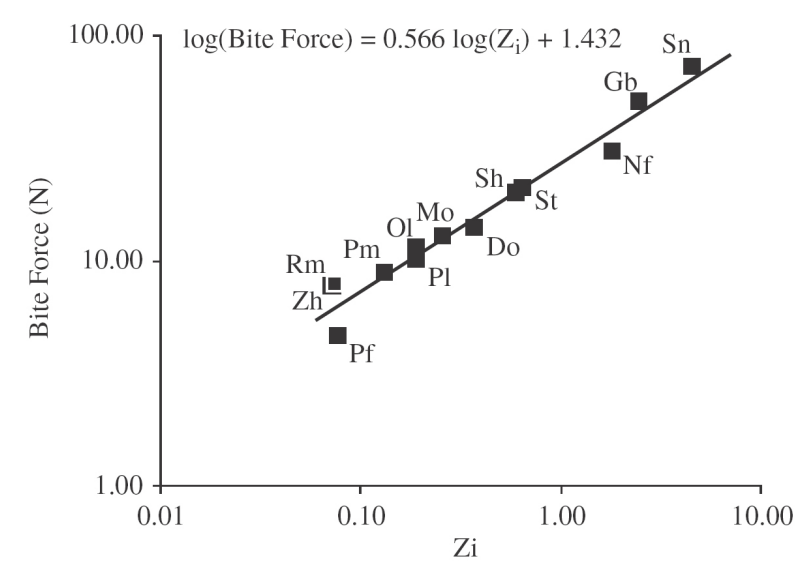

Figure 3. Scattergram of incisor strength index $\left(\mathbf{Z}_{\mathbf{i}}\right)$ and bite force. Regression line for all of the data is also plotted. Abbreviations are the same as in Figure 2.

ogy. However, if omnivore and grazer are used as factors within the cricetids to analyze the residuals there is a statistically significant difference [general linear model (GLM) $F=5.473 ; \mathrm{P}<0.025 ; n=16,34$; however, adjusted $R^{2}$ is only 0.084$]$. The difference in residuals for grazers $(0.027)$ and omnivores $(-0.013)$ reflects a difference in bite force of only $10 \%$. Addition of four omnivorous non-cricetids to the analysis increases the statistical significance (GLM $F=9.69$; $\mathrm{P}<0.005 ; n=16,51$; adjusted $R^{2}$ is only 0.12 ).

Two species that did show large differences are the tree squirrel, S. niger, and the fossorial G. bursarius. The GLM analysis between these species individually and the omnivores and grazers were highly significant (G. bursarius: $F=$ 127; $P<1 \times 10^{-16} ; n=5$, 67; with adjusted $R^{2}=0.64$ and S. niger: $F=320 ; P<1 \times 10^{-30} ; n=22,67$ with adjusted $R^{2}$ $=0.78$ ). These species clearly have stronger bites for their size. Geomys bursarius has a higher residual than $S$. niger ( $F$ $=5.9, P<0.05 ; n=5,22$; adjusted $R^{2}=0.158$ ).

Our second goal was to find a morphological measure to create a predictive model of bite force. As already seen, body mass would be highly effective within the omnivore/ grazers $\left(R^{2}=0.97\right)$. However, the hard biting $S$. niger and $G$. bursarius deviate from this pattern and when included reduce the correlation (Figure 2 and $R^{2}=0.90$ ). We used regressions of $\log$ bite force with $\log$ body mass, $\mathbf{A}, \mathbf{Z}$, and $\mathbf{S}$ for both positions on the dentary to find the best model to predict bite force. We compared the success of these models with the AIC index (Table 2). Although all regressions were highly significant (all $P$-values $<0.00001$ ), the AIC weights indicate both body mass and $\mathbf{S}_{\mathrm{d}}$ are relatively inferior predictors compared with the $\mathbf{A}$ and $\mathbf{Z}$ indices. The AIC weight is the amount of evidence in favor of a model (Burnham \& Anderson, 2002), and it can be seen in Table 2 that the preferred model is $A_{d}$ with $Z_{i}$ only slightly less likely. The $\log -\log$ plot of $\mathbf{Z}_{\mathbf{i}}$ to bite force is shown in Figure 3 . The regression equation is $\log 10$ (bite force) $=0.559$ $\log 10\left(\mathbf{Z}_{\mathbf{i}}\right)+1.432$. The regression equation using $\mathbf{A}_{\mathbf{d}}$ is $\log$ $10($ bite force $)=0.825 \log 10\left(\mathbf{A}_{d}\right)+0.613$. These equations are our best predictors of bite force based on morphology. 
Table 1. Sample size, mean and standard deviation (SD) for body mass and bite force

\begin{tabular}{lrcrcr}
\hline Species & $n$ & $\begin{array}{c}\text { Mass } \\
\text { (g) }\end{array}$ & SD & $\begin{array}{c}\text { Bite } \\
\text { force }(N)\end{array}$ & SD \\
\hline Dipodomys ordii & 11 & 63 & 6.77 & 13.98 & 2.07 \\
Geomys bursarius & 5 & 153 & 27.23 & 50.61 & 7.62 \\
Microtus ochrogaster & 10 & 34 & 6.36 & 12.88 & 2.86 \\
Neotoma floridana & 15 & 321 & 67.48 & 30.26 & 4.35 \\
Onychomys leucogaster & 2 & 34 & 13.43 & 11.45 & 1.14 \\
Perognathus flavescens & 1 & 6.5 & & 4.64 & \\
Peromyscus leucopus & 10 & 23 & 4.9 & 10 & 2.32 \\
Peromyscus maniculatus & 4 & 21 & 2.58 & 8.83 & 1.22 \\
Reithrodontomys megalotis & 3 & 11.5 & 2.29 & 7.67 & 0.43 \\
Sigmodon hispidus & 6 & 105 & 80.28 & 19.87 & 7.46 \\
Sciurus niger & 22 & 588 & 87.34 & 72.95 & 10.19 \\
Spermophilus tridecemlineatus & 4 & 144 & 31.98 & 21.05 & 4.35 \\
Zapus hudsonius & 1 & 24.5 & & 7.63 & \\
\hline
\end{tabular}

\section{Discussion}

Body mass and bite force are highly correlated among cricetids of this study (Figure 2). Perhaps within the omnivores this should not be a surprise. Although species within this feeding group can be classified as omnivore, granivore and even carnivore (Onychomys), there is considerable dietary overlap (Landry, 1970). A higher bite force has been postulated for the more carnivorous Onychomys as compared with the more omnivorous Peromyscus (Satoh \& Iwaku, 2006). This is not consistent with our data; we only have two measurements of bite force in Onychomys, but they are similar to bite forces in Peromyscus (Table 1). Also the strength indices $\mathbf{Z}$ and $\mathbf{A}$ are similar for Onychomys and Peromyscus (Figure 3). Adding the non-cricetids (omnivorous Spermophilus, heteromyids, and Zapus) did not change this pattern. The two more specialized grazers, Sigmodon and Microtus, did show differences that while statistically significant, were small in absolute amounts. The largest differences were between the main omnivore-grazer group and the durophagus $S$. niger and fossorial G. bursarius. Here the differences are large. For example, G. bursarius bites with a force over twice that of a similarly sized omnivorous cricetid.

Readers familiar with phylogenetically independent contrasts (Garland et al., 1999) will probably be troubled by our statistical inference here. We can clearly say that individuals of $S$. niger bite harder on average than this sample of cricetids, but we cannot rigorously ascribe that difference to the squirrel's durophagy. The independent contrast approach insists we need to have several independent evolutions of rodents from omnivory to durophagy to test this hypothesis. The same holds true for the fossorial Geomys. It bites hard, but is that related to its fossorial life style? We need independently derived fossorial forms such as Spalax and Ctenomys to test the role of life style. The difference of $S$. niger and G. bursarius from the rest of the rodents in this study should probably be considered suggestive rather than statistical evidence for a strong correlation of bite force and durophagy or fossorial habit.
Table 2. R-squares, AIC values, deltas and weights showing $\mathbf{A}_{d}$ and $\mathbf{Z}_{\mathbf{i}}$ are the best and $\mathbf{S}_{\mathbf{d}}$ the worst predictors of bite force

\begin{tabular}{lcccl}
\hline Index & $R^{2}$ & AIC & delta & $\begin{array}{c}\text { AIC } \\
\text { weight }\end{array}$ \\
\hline Mass & 0.903 & -16.25 & 10.68 & 0.005 \\
$\mathbf{A}_{\mathbf{d}}$ & 0.957 & -26.93 & 0 & 1 \\
$\mathbf{Z}_{\mathbf{d}}$ & 0.934 & -21.24 & 5.69 & 0.058 \\
$\mathbf{S}_{\mathbf{d}}$ & 0.833 & -9.23 & 17.7 & 0 \\
$\mathbf{A}_{\mathbf{i}}$ & 0.946 & -24 & 2.93 & 0.231 \\
$\mathbf{Z}_{\mathbf{i}}$ & 0.956 & -26.52 & 0.41 & 0.815 \\
\hline
\end{tabular}

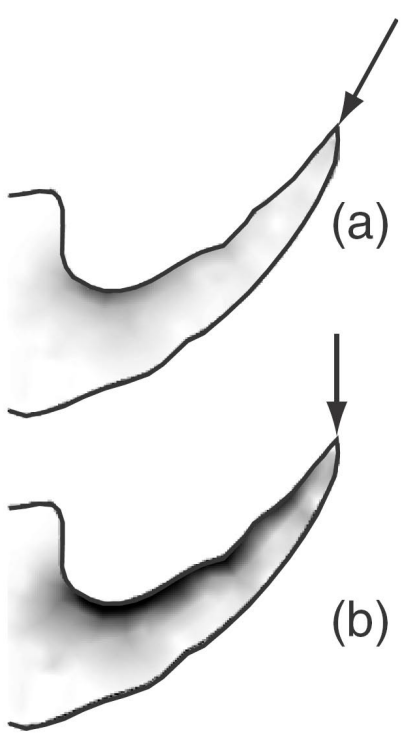

Figure 4. Results from FEA where in (a) the load was applied nearly parallel to the long axis of the incisor. In (b) the load was applied more perpendicular to the jaw. Bending stress is shown as dark shading. Maximal bending stress is over twice as high in (b).

$\mathbf{Z}_{i^{\prime}}$ a measure of rigidity to bending, is highly predictive of bite force with $R^{2}$ of 0.96 (Figure 3). However, we also need to emphasize the resounding failure of $\mathbf{S}_{\mathrm{d}}$ to predict bite force. In fact, it is the worst model in this study (Table 2). Clearly $S_{d}$ is the most closely tied to our predictions of bending strength (equations 3 and 4), where both the cross-sectional information of the beam and the input arm of the load are used to predict strength. The failure of $\mathrm{S}_{\mathrm{d}}$ brings into question our underlying assumptions about modeling jaw movement and calculating bending strength in rodents. Analysis of the jaw mechanics of the rat (Rattus) indicates that when gnawing hard foods the motion of the lower jaw is both forwards and upwards (Hiiemae \& Ardran, 1968). Thus, the rat's lower jaw does not swing shut by pivoting at the jaw joint. However, it was this simple pivoting model that we used as the basis for our calculation of the moment arm $l_{x}$ in Figure 1.

If there is an important forward as well as upward component to jaw motion it would alter the distribution of stresses in the jaw. This can be seen in the results of two FEAs with different models of jaw motion (Figure 4). In part (a), the angle of the load is a result of both the upward 
and forward motion of the lower jaw and is more consistent with the Hiiemae \& Ardran (1968) model. The hinged jaw is modeled in Figure $4(\mathrm{~b})$ where there is only an upward motion to the jaw and the load is applied directly down onto the incisor. The result is that bending stress is over twice as high in part (b) and bending stresses dominate. As the load vector moves more axially, the stresses switch more to axial compression.

The lack of predictive power of $\mathbf{S}_{\mathbf{d}}$ in our analysis coupled with the work of Hiiemae \& Ardran (1968) suggests that our original model of loading of the lower jaw and hence our measure of $l_{x}$ may reflect only part of the forces impinging on the rodent mandible. There is a protrusion and retraction component, called propalinal movement (Landry, 1959), that separates the function of gnawing at the incisors from the grinding function at the molars that can be found across the diversity of sciuromorphous, histricomorphous, and myomorphous rodents (Vaughan et al., 2000). However, a more detailed understanding of the forward and upward motion of the jaw, especially when gnawing, would be needed to estimate bending stresses. Fortunately, $\mathbf{Z}_{\mathbf{i}}$ and $\mathbf{A}_{\mathbf{d}}$ are easily measured and are very good predictors of bite force in rodents at the incisors.

Although $\mathbf{Z}_{\mathbf{i}}$ and $\mathbf{A}_{\mathbf{d}}$ were about equally predictive of bite force (Table 2), we prefer the incisor measurements. The diastema is more complex in shape and difficult to measure and this could introduce errors especially when more than one person is taking the measurements. Also slight differences in the orientation of the root of the lower incisor altered the lower outline of the dentary in such a way as to make us less confident in the repeatability of these measurements. In contrast, the lower incisors are easily measured with clear endpoints. For this reason we suggest the use of $\mathbf{Z}_{\mathbf{i}}$ to predict bite force.

\section{Acknowledgments}

We thank the University of Nebraska Agricultural Research Division, the School of Natural Resources, and the University of Nebraska State Museum for support. We also thank K. Geluso, K. N. Geluso, and M. F. Lemen for their help in the field.

\section{References}

Aguirre, L. F., Herrel, A., Van Damme, R. \& Matthysen, E. (2002). Ecomorphological analysis of trophic niche partitioning in a tropical savannah bat community. Proc. Roy. Soc. Lond. Ser. B. 269, 1271-1278.

Binder, W. J. \& Van Valkenburgh, B. (2000). Development of bite strength and feeding behaviour in juvenile spotted hyena (Crocuta crocuta). J. Zool. (Lond.) 252, 273-283.
Burnham, K. P. \& Anderson, D. R. (2002). Model selection and multimodel inference: a practical information-theoretical approach, 2nd edn. New York: Springer-Verlag.

Freeman, P. W. \& Lemen, C. (2008). Measuring bite force in small mammals with a piezo-resistive sensor. J. Mammal. 89, 513-515.

Garland, T., Midford, P. E. \& Ives, A. R. (1999). An introduction to phylogenetically based statistical methods, with a new method for confidence intervals on ancestral values. Am. Zool. 39, 374-388.

Hiiemae, K. (1971). The structure and function of the jaw muscles in the rat (Rattus norvegicus L.). III. The mechanics of the muscles. Zool. J. Linn. Soc. 50, 112-132.

Hiiemae, K. M. \& Ardran, G. M. (1968). A cinefluorographic study of mandibular movement during feeding in the rat (Rattus norvegicus). J. Zool. (Lond.) 154, 139-154.

Landry, S. O. 1959. The inter-relationships of the new and old world hystricomorph rodents. Univ. Calif. Publ. Zool. 56, 1-118.

Landry, S. O. (1970). The Rodentia as omnivores. Q. Rev. Biol. 5, 351-368.

Maynard Smith, J. \& Savage, R. J. G. (1959). The mechanics of mammalian jaws. School Sci. Rev. 141, 289-301.

Meers, M. B. (2002). Maximum bite force and prey size of Tyrannosaurus rex and their relationships to the inference of feeding behaviour. Hist. Biol. 16, 1-12.

Popov, E. P. (1999). Engineering Mechanics of Solids. New Jersey: Prentice-Hall.

R Development Core Team. (2005). R: A language and environment for statistical computing. R Foundation for Statistical Computing. Vienna, Austria: R Development Core Team ISBN 3-900051-07-0, http://www. r-project. org.

Satoh, K. \& Iwaku, F. (2006). Jaw muscle functional anatomy in northern grasshopper mouse, Onychomys leucogaster, a carnivorous murid. J. Morphol. 267, 987-999.

Thomason, J. J. (1991). Cranial strength in relation to estimated biting forces in some mammals. Can. J. Zool. 69, 2326-2333.

Turnbull, W. D. (1970). Mammalian masticatory apparatus. Fieldiana Geol. 18, 149-356.

Van Valkenburgh, B. \& Ruff, C. B. (1987). Canine tooth strength and killing behaviour in large carnivores. J. Zool. (Lond.) 212 , 379-397.

Vaughan, T. A., Ryan, J. M. \& Czaplewski, N. J. (2000). Mammalogy, 4th edn. New York: Saunders College Publishing.

Wroe, S., McHenry, C. \& Thomason, J. (2005). Bite club: comparative bite force in big biting mammals and the prediction of predatory behaviour in fossil taxa. Proc. Roy. Soc. Lond. Ser. B. 272, 619-625. 